\title{
As estratégias de contratação de mão de obra no setor portuário à luz da teoria da agência
}

\author{
The strategies of hiring manpower at port sector by agency theory perspective
}

\author{
Alex Sandro Quadros Weymer ${ }^{[a]}$, Belmiro Valverde Jobim Castor ${ }^{[b]}$
}

[a] Doutorando em Administração pelo programa de Pós-Graduação em Administração da Pontifícia Universidade Católica do Paraná (PPAD/PUCPR), professor da Pontifícia Universidade Católica do Paraná, Curitiba, PR - Brasil, e-mail: alex.weymer@pucpr.br

[b] PhD in Public Administration, professor titular da Pontifícia Universidade Católica do Paraná (PUCPR), Curitiba, PR - Brasil, e-mail: belmiro.castor@pucpr.br

\section{Resumo}

O objetivo do presente artigo foi verificar de que maneira a reconfiguração do setor portuário, notadamente a partir da Lei de Modernização dos Portos, influenciou na maneira como operadores portuários gerenciam a mão de obra de suas operações, que, outrora, era predominantemente de responsabilidade dos sindicatos. Para atingir o objetivo proposto, utilizou-se a metodologia da análise de conteúdo, com suporte da teoria da agência, que serviu para explicar a relação entre principal e agente, uma vez que os operadores portuários, condicionados por elementos regulativos como forma impositiva da contratação da mão de obra sindical, estão tentando mudar gradativamente os "agentes" dessa relação, ou seja, de trabalhadores avulsos para funcionários com vínculo empregatício, nos casos em que a relação custobenefício é compensatória. Conclui-se que o direito da prioridade dos sindicatos para prestação de serviços, secularizado através dos tempos, embora tenha sido assimilado pelos operadores portuários privados, existe uma "inconformada conformidade" às regras, não somente pelas limitações de gerir os recursos humanos, mas especialmente em razão dos altos custos vinculados aos trabalhadores avulsos.

Palavras-chave: Teoria da agência. Setor portuário. Competitividade.

\section{Abstract}

This paper aims to analyze how the port sector reconfiguration, particularly after the enactment of the Ports Modernization Act, has influenced how the port operators manage their operation manpower, which was beforehand 
a responsibility of the labor unions. To achieve the main objective, we have used content analysis supported by agency theory, explaining the principal-agent relationship, since port operators, constrained by legal regulations to hire union-controlled manpower, are trying to change gradually this scenario, substituting temporary workers with permanent staff, in the situations in which it does not represent extra hiring costs. This study allowed us to learn that the unions' priority to provide services for the port sector, entrenched over time, although assimilated by private port operators, does not eliminate the fact that there is a dissatisfied submission to the sector rules, not only due to the limitations of managing human resources, but especially because of the high costs related to temporary workers.

Keywords: Agency theory. Port sector. Competitiveness.

\section{Introdução}

Apesar do crescente interesse acadêmico e empresarial em utilizar o setor portuário e as organizações que fazem parte desse contexto como nível de análise, a maioria dos trabalhos foca aspectos logísticos como unidade de análise, negligenciando aspectos mais abrangentes para melhor compreensão da complexidade que permeia as relações desse setor. Isso não significa desmerecer tais trabalhos, pelo contrário, uma vez que se trata de um segmento estratégico da cadeia produtiva que liga os produtos e serviços ao mercado externo e, portanto, oferece dados extremamente significativos relacionados a aspectos econômicos que subsidiam decisões estratégicas.

Todavia, entende-se que analisar as relações existentes entre os diversos atores sociais que estão imersos em uma rede relacionamentos permite uma compreensão mais abrangente que vai além de aspectos logísticos, por meio da descrição e explicação de outras variáveis implícitas, mas que estão presentes nessas relações, condicionando ações recursivamente ligadas pelas próprias percepções dos agentes envolvidos e, consequentemente, de suas ações. Nesse sentido, Gulati (1998) considera que o contexto social em que as organizações estão imersas é fundamental para essa compreensão.

Entre os diversos atores sociais que fazem parte da complexa rede de relacionamentos do setor portuário, o objeto de análise desse estudo pauta-se na influência da reconfiguração do setor portuário sobre as estratégias de contratação de mão de obra dos operadores portuários, notadamente, em relação à tendência de substituição dos trabalhadores portuários avulsos por funcionários. Entende-se como trabalhador avulso aquele vinculado aos sindicatos dos estivadores, arrumadores e conferentes, e que está ligado ao Órgão Gestor de Mão-de-Obra (OGMO).
Esse recorte parece bastante atrativo, considerando que, antes da Lei de Modernização dos Portos iniciada com a Lei n. 8.630/93, com o objetivo de incentivar a competitividade intra e interportos, mediante o repasse das operações portuárias da iniciativa estatal para a privada, os sindicatos tinham autonomia não somente para definição de escalas de trabalho, mas também de treinamento, capacitação, remuneração e qualquer outra atividade relacionada à prestação de serviços no setor portuário.

A partir dessa mudança estrutural condicionada por variáveis políticas, econômicas, sociais e, especialmente, concorrenciais, os trabalhadores avulsos "filiados aos sindicatos" passaram a responder diretamente ao OGMO, que serve como um canal de comunicação entre operadores portuários e trabalhadores. Em outras palavras, as empresas do setor portuário, privadas ou não, são obrigadas a recrutar trabalhadores avulsos por meio de OGMO, fato que gerou uma série de desconfortos, que incluem desde relações de poder até leis normativas que foram secularizadas no decorrer do tempo, garantindo legitimidade de direitos sindicais, mas parecem estar perdendo forças diante de interesses privados, que serão tratados no decorrer deste trabalho.

Diante do exposto, o objetivo do presente trabalho foi verificar qual a influência da reconfiguração do setor portuário sobre as estratégicas de contratação de mão de obra e explicar, à luz da teoria da agência, se os custos assumidos pelo principal - nesse caso, os operadores portuários-, no monitoramento e controle do agente, são elementos fundamentais para o desejo de se desvincularem definitivamente dos sindicatos. Para esse propósito, foram obtidos dados parciais, a partir da dissertação de mestrado desenvolvida por Weymer (2005), que serviram de subsídios para identificar a posição e o grau de importância atribuído por diversos atores sociais, em relação aos 
sindicatos, por meio da técnica de análise de redes e, posteriormente, de entrevistas em profundidade com presidentes de sindicatos patronais, presidentes dos trabalhadores avulsos, presidente do OGMO e de gestores dos operadores portuários.

A contribuição teórica desse estudo visa a contribuir com um recorte interorganizacional da teoria da agência, considerando o contexto e suas variáveis, indo além das relações internas, que são tradicionalmente utilizadas nessa teoria. A contribuição prática pauta-se na necessidade de ampliar o conhecimento sobre o setor portuário, já que é um segmento-chave na cadeia logística, permitindo que países sejam competitivos no cenário mundial.

Sendo assim, o trabalho está estruturado da seguinte maneira:

1) breve contextualização do setor e do objeto de análise, já apresentada;

2) quadro teórico de referência sobre teoria da agência, contexto portuário e perfil do trabalhador avulso;

3) análise e apresentação dos dados;

4) considerações finais.

\section{Quadro teórico de referência}

\section{Teoria da agência}

Jensen e Meckling (1976), ao sugerirem as relações entre as empresas como um complexo de contratos, desenvolveram a teoria da agência, considerando que o conceito de agente-principal tem sua raiz no utilitarismo econômico proposto por Ross (1973). Nessa perspectiva, a partir de um processo de delegação de autoridade e atribuições, existem dois personagens com papéis bem definidos em suas relações contratuais, nos termos definidos por esses autores: o principal, que representa aquele ator social que detém a posse da organização ou delega alguma atribuição a outro, que no caso deste estudo são os operadores portuários; e o agente, que é representado pelos executores ou contratados, sob comando principal, que no caso deste estudo são os trabalhadores portuários avulsos com intermediação do OGMO.

Como toda relação de interesse econômico, as relações entre principais e agentes podem ser permeadas tanto de cooperação quanto de conflitos. De acordo com Eisenhardt (1989), um dos principais problemas está relacionado à incompatibilidade de interesses a partir de objetivos conflitantes, além da dificuldade em verificar, por parte do principal, se o agente está agindo de acordo com seus interesses. Outro aspecto importante apontado por essa autora está ligado ao fato de o principal assumir o risco da negociação, exigindo diferentes ações para diferentes situações.

De maneira mais específica, Jensen e Meckling (1976) apontam pelo menos três problemas de agência:

1) seleção adversa: o principal não consegue identificar se o agente possui as habilidades necessárias ao desempenho de uma função;

2) risco moral: o principal não consegue identificar se o agente está se esforçando da melhor maneira para atingir os objetivos estabelecidos;

3) oportunismo: comportamento inadequado de uma parte, demandando da outra um retorno superior ao previamente acordado, após essa outra parte ter realizado investimentos em ativos específicos.

Ainda de acordo com esses autores, os custos totais de agência incluem o montante gasto no monitoramento pelos principais, os custos da dependência dos agentes e a perda residual do principal. Em relação aos custos de monitoração, estão incluídos o sistema de informações, auditoria externa ou interna, conselho fiscal, entre outros aspectos que têm como objetivo acompanhar o comportamento do agente. Nos custos de dependência do agente, existe a possibilidade de conflito, uma vez que é necessário haver uma contrapartida entre os interessados. A perda residual decorre da redução do pagamento de dividendos ou comprometimento de fluxos futuros da firma que seriam transferidos aos acionistas, credores residuais. Nesse sentido, é importante destacar que, independente da manifestação ou não de conflitos entre os atores sociais, sempre existirão os custos.

Outro aspecto importante a ser considerado está em analisar a relação entre interesses individuais e coletivos, considerando o contexto e outras variáveis condicionadoras provenientes do ambiente coletivo no qual os envolvidos estão imersos. Diante de um contexto cada vez mais dinâmico e competitivo, 
informações parciais sobre o principal e o agente podem resultar em decisões baseadas em racionalidades limitadas e estimular a defesa de interesses individuais (EISENHARDT, 1989).

Reconhecendo que um dos pontos mais significativos e problemáticos é a dificuldade de monitorar o esforço dos atores econômicos envolvidos em uma transação, a elaboração dos contratos pode se tornar um problema, uma vez que devem ser incluídos esquemas de incentivos baseados no desempenho observado. Todavia, mesmo com a existência de um contrato formal entre as partes, a relação e o cumprimento dos dispositivos contratuais se enquadram em um contexto de assimetria das informações, resultando em contratos que não contemplam todas as variáveis envolvidas.

Esse problema se torna ainda mais grave quando a relação entre principal-agente é baseada em caráter de cunho político-legal. Lima (2005), ao estudar sobre informação e regulação da assistência suplementar à saúde, argumenta que a regulação possui todas as características de um problema principalagente, uma vez que a organização tem o objetivo de maximizar sua riqueza e o agente tem o objetivo de tirar a maior vantagem possível da riqueza da organização (BESANKO, 2005). Nesse sentido, em uma situação de interesse mútuo, é possível esperar que ambas as partes busquem estruturar sua relação de modo a contornar os problemas de informação e oportunismo; mas em uma relação em que o principal é obrigado, por força regulamentadora externa à organização, a contratar determinado agente, os conflitos podem atingir proporções bastante significativas.

A pesquisa de Christen, Iyer e Soberman (2006) destaca que o modelo de relação principal-agente é útil para salientar o que determina a escolha de determinadas estruturas regulatórias e determinados tipos de comportamento, uma vez que o que caracterizará a performance do agente é o esforço despendido por este, que, por sua vez, será diretamente responsável por sua satisfação ou insatisfação com o trabalho. Todavia, em uma situação em que a relação é condicionada por leis reguladoras e que, na maioria das vezes, o contrato é mais interessante para uma das partes, esse equilíbrio tende a ser muito mais difícil de ser atingido.

Nesse caso, as dificuldades nas relações entre principal/agente surgem porque os interesses de ambas as partes diferem de alguma forma. Nessa linha de pensamento, Besanko et al. (2005, p. 468, grifo nosso) argumentam que: o objetivo do principal é maximizar a diferença entre o valor que recebe como resultado das ações do agente e qualquer pagamento que faça ao agente. $\mathrm{Na}$ ausência de algum mecanismo para alinhar os interesses de ambas as partes, o agente fica propenso a não se importar com o valor gerado para o titular [...] $o$ agente se preocupa com o valor que recebe pela participação na relaşão, menos quaisquer custos em que incorra para fazêe-lo.

Ainda para Besanko (2005), problemas de agência poderiam ser resolvidos se fosse factível fazer um contrato completo, ou seja, estipulando as responsabilidades e os direitos de cada parte e todas as contingências que possam concebivelmente surgir durante a transação. Embora a elaboração de contratos completos seja pouco viável em uma relação entre empresas e funcionários diretos, por conta de variáveis difíceis de mensurar e estimar, contratos de mão de obra indireta parecem, a priori, oferecer menores dificuldades para definição de critérios para pagamentos (sem considerar a satisfação), embora tragam consigo uma série de outros problemas relacionados ao poder, como é o caso do setor portuário (VIEIRA; VIEIRA, 2000; WEYMER, 2005; WEYMER; MACHADO-DA-SILVA, 2006).

\section{O perfil do trabalhador avulso na dinâmica competitiva do setor portuário}

Nascimento (1999) faz uma importante constatação em relação aos impactos da Lei de Modernização dos Portos sobre o movimento sindical. De acordo com esse autor, a emergência de um novo paradigma tecnológico e organizacional tem influenciado os sindicatos portuários, modificando o padrão de distribuição do trabalho no segmento e favorecendo o surgimento de um novo trabalhador portuário: dotado de maiores habilidades cognitivas, multifuncional, polivalente e participativo, abrindo espaço para a consolidação de uma cultura de empresa do setor.

Esse novo perfil desejado, mas que ainda depende de uma mudança cultural que ainda está arraigada, deve-se especialmente à criação do OGMO, a partir da Lei 8.630/93. Nesse sentido, fica claro por meio dessa lei que o sistema de gerenciamento da mão de obra avulsa é alterado na medida em que 
é introduzido o contrato coletivo de trabalho, com função deliberativa, e o OGMO, com função executiva. Até a promulgação da Lei 8.630, cabia ao Estado o papel de regulamentar o processo de operação e contratação da mão de obra em atividades portuárias, no qual os próprios sindicatos distribuíam as tarefas em ternos, avaliavam o desempenho e repassavam o pagamento aos trabalhadores filiados.

Assim, percebe-se nitidamente a perda de autonomia dos sindicatos com a implantação do OGMO, com a redefinição do gerenciamento da força de trabalho portuária, retirando tal papel dos sindicatos, tradicionais gestores. Essa mudança provocou reações defensivas durante muito tempo por parte dos sindicatos e também dos operadores portuários, que continuam contratando a mão de obra avulsa sindical, agora intermediada pelo OGMO. É importante ressaltar que, embora o OGMO seja o elo entre o operador portuário e os sindicatos, nada impede que sejam feitas negociações em forma de contrato ou convenção coletiva, diretamente entre as partes, com vigência de dois anos (o operador portuário seria representado pelo sindicato patronal ou, no caso de acordos coletivos, diretamente entre os sindicatos e operadores portuários).

O ponto crítico dessa discussão é justamente o fato de existir uma contradição em relação ao objetivo principal da Lei de Modernização, que é repassar à iniciativa privada maior autonomia para investimentos no setor portuário, por meio da gestão das operações portuárias. Tal contradição acontece a partir do momento em que existe uma limitação que os operadores portuários têm na contratação de mão de obra própria e, consequentemente, na elaboração de estratégia de incentivos, estabelecimento de critérios e políticas internas no que tange à gestão de pessoal.

\section{Metodologia}

\section{Delineamento e delimitação}

A presente pesquisa é classificada como predominantemente qualitativa e de concepção descritiva e explicativa. A amplitude temporal do estudo é transversal, sendo utilizados dados em dois momentos distintos do mesmo contexto, apresentando, portanto, dois cortes transversais. A pesquisa adota o nível de análise organizacional e, como unidade de análise, os principais dirigentes das organizações.

\section{Coleta dos dados}

O ponto de partida deste estudo foi identificar as principais organizações que fazem parte do contexto portuário e que mantêm uma relação direta ou indireta com os trabalhadores avulsos, especialmente após a implantação da Lei 8.630/93, conhecida como Lei de Modernização dos Portos. Para esse propósito foi utilizado como base o trabalho realizado por Weymer (2005), que mapeou e planificou, por meio da técnica da análise de redes, as organizações integrantes da rede de relacionamentos do setor portuário no Sul do Brasil, com uso do software UCINET, que constitui programa computacional para análise de redes. Essa base inicial permitiu algumas inferências complementares com um recorte teórico à luz da teoria da agência, que não era objetivo de análise do trabalho daquele autor.

A segunda etapa foi aplicar entrevistas em profundidade nas principais organizações que mantêm uma relação direta com os trabalhadores avulsos, independendo se a base da relação era cunho obrigatório ou voluntário. Nesse sentido, foram selecionadas dez organizações que fizeram parte da planificação da rede: três sindicatos dos trabalhadores - estivadores, arrumadores e conferentes; dois sindicatos patronais; a superintendência do porto; dois agentes marítimos; dois despachantes aduaneiros; e um operador portuário, que detinha aproximadamente $95 \%$ da movimentação de contêineres daquele porto, sendo praticamente um monopólio natural, já que possui o direito de uso do espaço portuário por 25 anos, sendo prorrogável por mais 25 anos.

\section{Plano de análise dos dados}

Todas as entrevistas foram transcritas integralmente, inclusive mantendo a linguagem, que, segundo Bardin (2009), permite uma classificação mais fidedigna no momento da codificação, ao considerar a palavra, como uma das etapas iniciais, como unidade de registro. Nesse sentido, a técnica de análise de dados utilizada foi a análise de conteúdo, que se constitui de procedimentos apropriados para o conhecimento e a sistematização de recepção de 
mensagens à medida que enfoca a presença ou a ausência de categorias ou características na comunicação com os entrevistados.

De acordo com Bardin (2009), os procedimentos sistemáticos em relação às mensagens (quantitativos ou não) permitem a inferência de conhecimentos relativos às condições de produção/recepção (variáveis inferidas) dessas mensagens. A inferência, nesse caso, tem um significado bastante explícito e pressupõe a comparação dos dados obtidos mediante discursos e símbolos, com os pressupostos teóricos de diferentes concepções de mundo, de homem e de sociedade.

No caso da situação em estudo, foi possível identificar que as palavras regulamentos, obrigação, direito adquirido, leis e custos apareceram constantemente em todos os discursos dos entrevistados, sendo as posições de concordância diferentes à medida que tais "condicionamentos" eram prejudiciais ou benéficos, sob a perspectiva dos diferentes entrevistados. Como forma complementar de garantir a fidedignidade dos dados, também foram analisados documentos, leis e acordos coletivos, além de entrevista com dois representantes do setor portuário de outro Estado do Sul do Brasil. Esse procedimento permitiu uma triangulação dos dados oriundos de múltiplas fontes, além de aumentar a confiabilidade dos resultados.

\section{Apresentação e análise dos resultados}

Impulsionado pela necessidade de responder mais rapidamente às exigências do mercado internacional, por meio de investimentos em tecnologias e forma de gestão alinhada ao atual contexto contemporâneo, pode-se afirmar que a Lei de Modernização de Portos é considerada um marco histórico. Embora existam diversas mudanças importantes a partir do arrendamento dos espaços públicos aos terminais privados, o objetivo deste estudo está pautado no impacto dessa reestruturação no perfil dos trabalhadores portuários avulsos. Nesse sentido, é apresentada, a seguir, a planificação de uma rede de relacionamentos entre organizações do setor portuário, destacando a posição dos sindicatos, do OGMO e do principal operador portuário privado da rede. $\mathrm{Na}$ sequência, é apresentada a análise das entrevistas aplicadas aos presidentes dos sindicatos e dos gestores representantes das empresas já apontadas na metodologia deste trabalho.

\section{Relacionando a reconfiguração estrutural do setor portuário com a posição dos sindicatos}

Com base no trabalho de Weymer (2005), foi possível identificar que a posição dos sindicatos em uma rede de relacionamentos com 39 atores sociais do porto de Rio Grande, RS, no Sul Brasil, apresenta um indegree de $50 \%$, ou seja, metade das organizações da rede identificada pelo autor indicava ter algum tipo de relacionamento com essas organizações. Essa densidade da rede - medida a partir do quociente das ligações efetivamente existentes entre os atores da rede pelo total de ligações possíveis entre eles aumenta à medida que as relações têm como base de relacionamento mecanismos regulamentadores.

Talvez a mudança mais significativa sobre o perfil do trabalhador portuário avulso (TPA) tenha sido a criação do OGMO nesse novo contexto competitivo do setor portuário, que, inclusive, ocupa lugar central na rede $(\mathrm{OG})$, ao contrário dos sindicatos dos trabalhadores, que ocupam lugares periféricos à rede $(\mathrm{SE}, \mathrm{SC}$ e $\mathrm{SA})$.

A assertiva precedente pode ser corroborada pela Figura 1, a partir das relações entre diferentes atores sociais, com destaque para fornecedores, operadores portuários, agências marítimas e despachantes aduaneiros (recorte intencional do total da rede de 39 organizações):

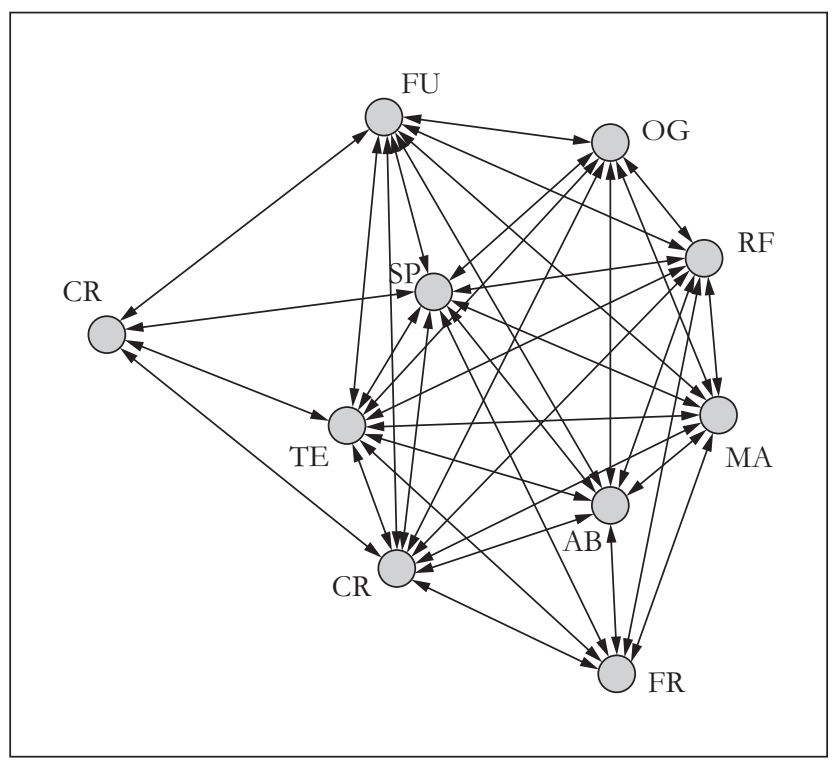

Figura 1 - Relações entre sindicatos patronais, laborais e OGMO

Fonte: WEYMER, 2005, p. 91. 
A Figura 1 evidencia de maneira ilustrativa a receptividade do OGMO (Código OG) em relação às outras organizações, já que existem vetores indicados em sua direção. Nesse momento, torna-se oportuno destacar que a empresa TE (Terminal de Contêineres) representa o principal operador portuário da rede, recebendo 100\% de indicações de todas as outras organizações. Vale ressaltar que a base de relacionamento é distinta: enquanto o TE destaca-se pela sua relevância econômica, exercendo uma relação de dependência com os outros, a base de relacionamento com o OGMO está sustentada por uma base político-legal.

Outro fator importante é que mesmo diante de um grau de receptividade de $50 \%$ em relação a outras organizações da rede, que incluem armadores (donos de navios), agências marítimas, despachantes aduaneiros, entre outros atores sociais ligados à área portuária, os sindicatos apresentaram um grau de importância insignificante na percepção dos 38 outros atores da rede, conforme Quadro 1.

\begin{tabular}{|c|c|c|c|c|c|c|c|c|}
\hline & & $\begin{array}{c}\text { Sem } \\
\text { importância }\end{array}$ & $\begin{array}{c}\text { Pouco } \\
\text { importante }\end{array}$ & Importante & $\begin{array}{c}\text { Muito } \\
\text { importante }\end{array}$ & Crucial & $\begin{array}{c}\text { Baixa } \\
\text { popularidade }\end{array}$ & $\begin{array}{c}\text { Alta } \\
\text { popularidade }\end{array}$ \\
\hline SP & 1 & 0 & 0 & 7 & 16 & 15 & 0 & 38 \\
\hline TE & 2 & 0 & 0 & 10 & 12 & 12 & 0 & 34 \\
\hline WS & 3 & 2 & 1 & 12 & 13 & 6 & 3 & 31 \\
\hline $\mathbf{R F}$ & 4 & 1 & 1 & 5 & 9 & 17 & 2 & 31 \\
\hline CT & 5 & 0 & 13 & 14 & 9 & 6 & 3 & 29 \\
\hline $\mathrm{CP}$ & 6 & 0 & 0 & 6 & 10 & 13 & 0 & 29 \\
\hline CR & 7 & 1 & 1 & 12 & 10 & 6 & 2 & 28 \\
\hline MS & 8 & 0 & 3 & 7 & 8 & 13 & 3 & 28 \\
\hline MA & 9 & 4 & 0 & 9 & 8 & 8 & 4 & 25 \\
\hline PB & 10 & 1 & 2 & 6 & 7 & 12 & 3 & 25 \\
\hline PR & 11 & 2 & 4 & 10 & 11 & 4 & 6 & 25 \\
\hline BU & 12 & 1 & 1 & 10 & 6 & 8 & 2 & 24 \\
\hline $\mathrm{AB}$ & 13 & 1 & 3 & 13 & 8 & 3 & 4 & 24 \\
\hline WI & 14 & 2 & 3 & 11 & 9 & 4 & 5 & 24 \\
\hline MA & 15 & 1 & 2 & 7 & 8 & 9 & 3 & 24 \\
\hline HA & 16 & 1 & 3 & 8 & 10 & 5 & 4 & 23 \\
\hline PE & 17 & 0 & 1 & 10 & 10 & 3 & 1 & 23 \\
\hline TR & 18 & 3 & 3 & 13 & 7 & 3 & 6 & 23 \\
\hline OG & 19 & 2 & 6 & 7 & 11 & 5 & 8 & 23 \\
\hline AL & 20 & 1 & 3 & 8 & 9 & 5 & 4 & 22 \\
\hline GR & 21 & 2 & 2 & 13 & 5 & 4 & 4 & 22 \\
\hline PO & 22 & 1 & 0 & 8 & 7 & 6 & 1 & 21 \\
\hline IP & 23 & 1 & 2 & 10 & 5 & 6 & 3 & 21 \\
\hline SN & 24 & 0 & 3 & 12 & 5 & 3 & 3 & 20 \\
\hline SD & 25 & 0 & 4 & 12 & 3 & 5 & 4 & 20 \\
\hline
\end{tabular}

Quadro 1 - Grau de popularidade entre as organizações da rede 


\begin{tabular}{llccccccc}
\hline & & $\begin{array}{c}\text { Sem } \\
\text { importância }\end{array}$ & $\begin{array}{c}\text { Pouco } \\
\text { importante }\end{array}$ & Importante & $\begin{array}{c}\text { Muito } \\
\text { importante }\end{array}$ & Crucial & $\begin{array}{c}\text { Baixa } \\
\text { popularidade }\end{array}$ & $\begin{array}{c}\text { Alta } \\
\text { popularidade }\end{array}$ \\
\hline ME & $\mathbf{2 6}$ & 1 & 2 & 8 & 6 & 5 & 3 & 19 \\
FU & 27 & 2 & 6 & 13 & 5 & 1 & 8 & 19 \\
CE & $\mathbf{2 8}$ & 0 & 3 & 12 & 4 & 2 & 3 & 18 \\
FR & $\mathbf{2 9}$ & 1 & 1 & 7 & 6 & 4 & 2 & 17 \\
BB & 30 & 1 & 7 & 9 & 7 & 1 & 8 & 17 \\
SC & 31 & 1 & 1 & 7 & 5 & 4 & 2 & 16 \\
JA & 32 & 4 & 6 & 14 & 2 & 0 & 10 & 16 \\
GE & 33 & 3 & 5 & 7 & 5 & 2 & 8 & 14 \\
SA & 34 & 4 & 3 & 3 & 8 & 2 & 7 & 13 \\
SE & 35 & 4 & 2 & 4 & 6 & 2 & 6 & 12 \\
SC & 36 & 4 & 2 & 4 & 6 & 2 & 6 & 12 \\
FE & 37 & 3 & 2 & 7 & 2 & 1 & 5 & 10 \\
CR & 38 & 4 & 3 & 8 & 1 & 0 & 7 & 9 \\
SI & 39 & 4 & 2 & 5 & 2 & 0 & 6 & 7 \\
\hline
\end{tabular}

Quadro 1 - Grau de popularidade entre as organizações da rede Fonte: WEYMER, 2005, p. 91.

Para identificar aquelas organizações com mais prestígio e popularidade, o autor demonstrou quais as que recebem mais contatos (indegree) e qual o nível de importância que elas representam sob o ponto de vista daquelas que as indicaram. A análise a partir do indegree ofereceu dados mais interessantes sobre a centralidade, pois cada organização ocupa uma posição em um ranking a partir da percepção de todos os outros atores da rede. No Quadro 1, percebe-se que a popularidade dos sindicatos estão nas posições 34, 35 e 36 do ranking e que, cada um, recebeu somente duas indicações de "crucial", ou seja, os próprios sindicatos indicaram um ao outro.

Diante do exposto, foi possível identificar a posição dos sindicatos sob a perspectiva de outras 38 organizações relacionadas ao setor portuário de maneira ilustrativa, a partir da metodologia de análise de redes, com base no trabalho de Weymer (2005). Com o objetivo de compreender os motivos e as bases que sustentam o relacionamento entre sindicatos e outras organizações da rede, a seguir serão apresentadas as percepções obtidas por meio de entrevistas em profundidade, com ênfase no depoimento de representantes dos operadores portuários (destaque em amarelo), de despachantes e agentes marítimos, além dos presidentes sindicais.

\section{Uma breve contextualização sobre os participantes envolvidos neste estudo}

Não é por acaso que a organização TE ocupou o $2^{\circ}$ lugar no ranking das organizações mais importantes da rede, uma vez que o alto investimento feito, por esse terminal privado, em tecnologia e infraestrutura permitiu o cumprimento de prazos preestabelecidos no contrato de arrendamento e, consequentemente, atingir um dos principais objetivos da Lei de Modernização: tornar o porto competitivo e altamente eficaz no atendimento às exigentes demandas de logística. Um dos principais motivos de esse ator ter ficado em $2^{\circ}$ lugar no ranking pode ser explicado pelo fato de que a superintendência do porto, embora tenha repassado as operações portuárias à iniciativa privada, tem um papel regulativo e fiscalizador de tudo o que acontece 
na área de sua jurisdição, assumindo, portanto, o $1^{\circ}$ lugar no ranking.

A contextualização citada é importante para o entendimento da proposta deste estudo, porque esse operador portuário é um dos que mais sofre condicionamento regulativo em relação à contratação de mão de obra. Outra inovação importante, não só para o porto de Rio Grande, mas para todos os portos do País, foi a criação dos Órgãos Gestores de Mão-de-Obra, o que mudou radicalmente o perfil do trabalhador avulso. Uma importante ressalva, neste momento, é que o "trabalhador avulso" é aquele registrado no OGMO, especialmente após a Lei 8.630/93. Embora não seja exigência, nos termos definidos por aquela lei todos os trabalhadores avulsos da rede são filiados nos seguintes sindicatos: estivadores, arrumadores e conferentes.

O OGMO é uma entidade com personalidade jurídica de direito privado, criada com força de lei para exercer algumas funções típicas do Estado, de acordo com um relato de um dos líderes sindicais. Uma das principais desconfianças dos sindicatos em relação ao OGMO, no início de sua implantação, foi justamente com relação à capacidade de esse órgão fornecer mão de obra aos operadores portuários, mesmo que esses trabalhadores não fossem sindicalizados. Logo, se hoje o trabalhador quiser sair do sindicato, ele permanece com direito ao trabalho, pelo menos em teoria, já que na prática não acontece dessa maneira.

Para acontecer isso, somente se o OGMO não tiver contingente suficiente para atender à demanda solicitada pelo operador portuário, em razão da prioridade, e não da exclusividade, da contratação da mão de obra avulsa, conforme já foi discorrido em parágrafos anteriores. Assim, a condição necessária para que um trabalhador avulso possa prestar serviços a determinado operador portuário é seu registro no OGMO, e não a filiação aos sindicatos.

As constatações precedentes podem explicar o motivo pelo qual os sindicatos dos trabalhadores avulsos, representados nesta rede pelos atores 28 (SE), 29 (SA) e 30 (SC), foram considerados pouco importantes, situados quase na região periférica da rede. Os sindicatos perderam força após a implementação da Lei 8.630, de modo que as suas atividades passaram a ser intermediadas pelo Órgão Gestor de Mão-deObra (ator 27), o que justifica a melhor posição desse último em relação aos sindicatos na rede, com o $19^{\circ}$ lugar. Ainda que o poder dos sindicatos tenha sido restringido, a lei garante a eles o direito e a prioridade dos trabalhos referentes à carga e à descarga de navios, conferência e operações em guindastes, direito que é bastante questionado por operadores portuários e que será tratado na fase subsequente.

\section{Os problemas da agência nas relações sob a perspectiva das organizações envolvidas}

A qualificação profissional dos trabalhadores portuários avulsos acontecia de maneira empírica antes da Lei 8.630/93, conforme depoimento de um dos presidentes sindicais: "nunca existiu uma escola apropriada na estrutura do ensino profissional maritimo que preparasse os trabalhadores avulsos, eles sempre se preparam no seio da própria categoria".

Embora a imitação de procedimentos e métodos de trabalhos e a unidade entre os trabalhadores - reflexo do orgulho construído historicamente pela classe - ainda aconteça nos dias de hoje, sua legitimação profissional acontecerá somente mediante cursos impostos pelas autoridades competentes, mediada pelo OGMO. Embora a capacitação do trabalhador avulso esteja sob responsabilidade desse órgão, alguns depoimentos dos representantes dos operadores portuários, despachantes aduaneiros e agência marítima questionaram a falta de liberdade para contratação de mão de obra própria e, consequentemente, a falta de garantia sobre as competências e o compromisso com os resultados esperados, considerando que a lógica empregatícia é diferente nessa relação.

Neste momento, torna-se oportuno resgatar um conceito importante da teoria de agência proposto por Eisenhardt (1989). De acordo com essa autora, quando existe uma incompatibilidade de interesses e objetivos conflitantes, provavelmente, o principal irá assumir o risco da negociação caso os agentes ajam somente de acordo com os seus interesses. De fato, no discurso dos entrevistados, percebe-se nitidamente uma relação, em processo de amadurecimento, que em alguns momentos foi repassada com certa mágoa e discordância com as leis impostas. Uma importante ressalva é que a constatação precedente sobre os agentes não foi identificada no levantamento de campo, mas sim a partir da percepção dos contratantes.

$\mathrm{Na}$ percepção dos presidentes dos sindicatos, os trabalhadores avulsos não somente possuem direito adquirido, pela própria história, como também 
estão preparados e capacitados para executarem os serviços demandados pelos operadores portuários, se houver predisposição das autoridades para oferta de atualização contínua. Essa concepção é compartilhada pelo discurso do presidente do OGMO. Todavia, sob a ótica dos gestores das empresas privadas, existe uma restrição em relação ao comprometimento, inclusive a ponto de, em determinadas situações, o contratante (principal) pagar duas vezes pelo serviço. Em outras palavras, cumpre-se a regulamentação de contratar o trabalhador avulso intermediado pelo OGMO, mas quem executa efetivamente o serviço são os funcionários internos.

Embora essa situação supracitada não seja generalizada, em condições de trabalho em que é necessário usar tecnologias caras ou que precisem de um treinamento mais avançado, essa prática é adotada para garantir que o risco assumido seja menos provável. Nesse sentido, o problema de agência acontece não pelo fato de falta de informação, mas por existir uma situação forçada permeada de conflito de interesses, mesmo que a intenção dos trabalhadores avulsos (nesse caso, os agentes) seja a melhor possível no desempenho do seu trabalho.

Independente da percepção dos diferentes atores sociais, o fato é que os sindicatos conquistaram uma legitimidade pela própria história, garantindo a essa classe, durante muito tempo, o controle e o "privilégio" de serem os únicos profissionais habilitados a exercer as funções a que se propõem. Esse controle disseminou um pensamento ideológico que ainda é preservado por alguns membros sindicais, que sofreu grande impacto após a Lei 8.630 e que gradativamente está sendo absorvido por uma lógica instrumental, norteada pela eficiência e pelos custos baixos almejados pelo atual cenário competitivo portuário. Essa constatação pode ser corroborada pela citação apresentada a seguir, retirada de uma parte do discurso do presidente do sindicato dos conferentes:

a mão de obra avulsa surge mesmo antes da existência do porto organizado, do agente, do armador [...] como essa mão de obra era extremamente necessária ao longo da história, os sindicatos passaram a conquistar um conjunto imenso de direitos na relaşão de trabalho, direitos decorrentes da própria importância desse trabalho, portanto, isso não se trata de privilégios [...].

Essa visão certamente não é compartilhada pelos operadores portuários que buscam equilibrar as expectativas divergentes entre a relação sindicato/ contratante, porém, buscando gradativamenteimpor seus interesses orientados por um principal fator: $\mathrm{o}$ custo. A mão de obra sindicalizada custa bem mais caro para a contratante (nesse caso, o operador portuário), que obrigatoriamente precisa requisitá-la no OGMO. Além disso, uma das grandes reclamações dos operadores é a falta de autonomia na contratação, na formação e no treinamento de mão de obra própria, como pode ser verificado a partir do seguinte discurso parcial do representante do principal operador portuário da rede de organizações em análise: "como é que você vai fazer uma empresa se tornar eficiente sem comprometimento? Não existe. E como você pode ter uma lei que incentive o cara a não ter vínculo empregatício?'.

Nesse ponto, percebe-se nitidamente o conflito de agência, especialmente em relação à dificuldade de garantir e medir o esforço atribuído vinculado à agregação de valor, além dos custos superiores em razão da dependência dos agentes, conforme apontado por Jensen e Meckling (1976), como sendo um dos principais problemas da agência. De fato, a relação se torna mais difícil e a elaboração de contratos, contemplando todas as variáveis envolvidas, muito mais complexa do que uma relação tradicional entre empregador/empregado.

Os sindicatos também entendem que a principal resistência por parte dos principais é o custo, conforme o depoimento de um líder sindical: "a questão é de custo. Porque se eles contratarem livremente no mercado num país de desemprego como nós, eles podem barganhar.".

É importante ressaltar que a prioridade garantida por lei ao trabalhador avulso não significa exclusividade. No caso de um operador portuário solicitar ao OGMO mão de obra e este não ter disponível o número de trabalhadores demandado, aquele pode contratar profissionais diretamente, condição assegurada pelo próprio acordo coletivo firmado entre sindicatos e operadores portuários. Considerando que dificilmente esse fato irá ocorrer, os operadores inevitavelmente precisam contratar a mão de obra registrada no OGMO, mantendo uma relação com os sindicatos baseada em uma "inconformada conformidade": para os trabalhadores interessa o quê? Que a contratante
pague, se o cara trabalhou ou não trabalhou, o cara está
lá. Essa é a relação, vai denunciar o quê? Vai denunciar
quando ela não estiver contratando, como já aconteceu
em alguns casos [...]. Como há uma indisposição em
receber esses funcionários, e esses funcionários têm uma

REBRAE. Revista Brasileira de Estratégia, Curitiba, v. 2, n. 3, p. 233-245, set./dez. 2009 
certa indisposição nesse processo sindical portuário, não é uma relação muito pacífica como nunca foi ao longo do tempo, historicamente. Então o que eles preferem? Ter os caras lá (avulsos) na quantidade definida pela legislação? Eles ficam lá, sentados, tomam café, aguardam o turno, acabou e vai embora. Isso acontece em todas elas.

Esse depoimento, retirado de parte do discurso de uma das organizações que têm relação indireta com os trabalhadores avulsos, evidencia a existência de conflitos e, consequentemente, o surgimento dos problemas de agência, especialmente em relação à seleção adversa, já que o contratante não consegue identificar se o agente possui as habilidades necessárias ao desempenho de uma função, bem como em relação ao risco moral, pela dificuldade de o principal não ter mecanismos eficientes para controlar se os trabalhadores avulsos (agentes) estão se esforçando da melhor maneira para atingir os objetivos estabelecidos.

Além desses aspectos relacionados aos problemas de agência, percebe-se que os custos de monitoração, de perda residual e de custos de dependência dos agentes são inerentes ao próprio dilema resultante dos conflitos. Nesse caso, o contexto apontado por Eisenhardt (1989) na base teórica deste trabalho assume papel significativo, uma vez que variáveis ambientes, externas às organizações, condicionam suas estratégicas, especialmente aquelas de caráter político-legal.

Embora o objetivo aqui não seja explicar todas as variáveis relacionadas a esse processo de mudança, é importante ressaltar que existem normas e regulamentos que dificultam ainda mais o entendimento entre principal/agente. Um deles, citado enfaticamente, tanto pelos sindicatos quanto pelo OGMO, é a limitação em definir quais os cursos necessários para capacitação dos trabalhadores avulsos e a dificuldade de aprovação de verba para os treinamentos. Do ponto de vista sociocultural, embora ainda existam alguns "ranços ideológicos" nos termos definidos por um dos entrevistados, a exigência da obtenção de diplomas que irão dar suporte legítimo aos trabalhadores avulsos e presidentes sindicais foi aceita, o que está sendo questionada é a maneira como estão sendo administrados e efetivados os treinamentos.

Hoje o OGMO vem com uma tarefa de criar e atender novos desafios, de promover cursos de informatização, etc., isso é importante [...], o que eu tenho questionado é a qualidade dos cursos que são oferecidos [...], en tenho solicitado sistematicamente ao OGMO cursos que podem ser atrativos e que podem realmente aumentar a qualidade do conferente no conbecimento que ele já possui, caso contrário o conferente é que vai ter que ser professor [...].

Esse pensamento, embora tenha partido de um líder sindical, parece ser justificável por dois motivos: primeiro, ainda não existem cursos específicos para formar estivadores, conferentes ou arrumadores; segundo, quem decide os tipos de cursos não são os sindicatos ou o OGMO, mas outros órgão reguladores, como a marinha, por exemplo. Nesse sentido, essa centralização é considerada um entrave para a evolução da profissionalização, pois muitos dos cursos oferecidos não condizem com as reais necessidades dos empregadores, o que dificulta ainda mais a relação entre principal/ agente, que, nesse caso, são os operadores portuários e trabalhadores avulsos. Embora as solicitações de cursos feitas ao OGMO não sejam atendidas, cabe lembrar que esse órgão é um intermediário e, muitas vezes, independe de seu esforço a efetivação dos cursos solicitados, já que a determinação de alguns deles é centralizada em outro órgão e as verbas são limitadas.

Nós temos um grave entrave na questão de treinamento porque a nossa verba de treinamento é administrada pela Marinha do Brasil, isso é uma verba que é um desconto que o operadorportuáriopaga [...] os currículos são feitospela marinha, né, eles sãofechados, tem que ser aquilo [...]um curso que nãoé reconhecidopela Marinha como um curso oficial, esse diploma não vale legalmente.

Sabe trabalhar, mas náo tem o papel. Então esse é o grande problema, a questão do treinamento.

O depoimento anteriormente citado é do presidente do OGMO e evidencia a difícil tarefa de conciliar interesses entre trabalhadores e empregadores. Por um lado, existe a predisposição em prover condições para aprimoramento profissional aos trabalhadores portuários avulsos, pois ele reconhece a necessidade da legitimação dos cursos oferecidos; e, por outro lado, existem restrições de cunho legal para adequar a qualificação ao patamar almejado pela atual dinâmica competitiva para prestar serviços aos operadores portuários privados.

\section{Considerações finais}

A reconfiguração do setor portuário, a partir da Lei 8.630, foi inevitável para garantir com- 
petitividade, tanto interportos quanto intraportos. Considerando a complexidade e a dinâmica do setor, e dos diversos atores sociais envolvidos, uma das consequências foi justamente a criação de normas e leis com o objetivo de regulamentar as relações necessárias para o desenvolvimento do setor. Após a análise da posição desprestigiada dos sindicatos no ranking de grau de importância identificado por Weymer (2005), e da "inconformada conformidade" por parte dos operadores portuários em contratar a mão de obra avulsa, conclui-se que, embora exista um cumprimento da lei em relação à contratação, existe um sentimento de perda e de insatisfação na relação principal/agente.

Essa insatisfação ocorre por diversos fatores, que parecem estar intimamente relacionados aos problemas de agência: custos elevados pagos aos trabalhadores avulsos pelos serviços prestados; falta de autonomia para seleção de profissionais internos; limitação de controle de ações individuais dentro do ambiente de trabalho; deficiência em treinamentos específicos, especialmente em atividades que envolvem tecnologia superior; além de a relação ter sido originada a partir de uma base político-legal e, portanto, condicionada.

Nesse sentido, foi possível perceber que os problemas de agência são ainda mais graves nas relações entre principal/agente, que acontecem de maneira não voluntária, nesse caso, entre os operadores portuários e os trabalhadores portuários avulsos, com intermediação do OGMO. Em situações pontuais e específicas, foi possível identificar manobras por parte do contratante, a ponto de ter o custo duplicado apenas para evitar que os trabalhadores avulsos executassem o serviço, evidenciando o desejo de substituir o agente da relação, ou seja, de trabalhador avulso para empregado com vínculo empregatício. Em casos específicos, de acordo com o depoimento de um dos presidentes sindicais, os operadores portuários chegaram a propor a alguns trabalhadores avulsos que se desvinculassem do OGMO e fossem trabalhar como empregados em suas empresas. Percebe-se, portanto, que existem ações estratégicas específicas com o objetivo de diminuir gradativamente a dependência dos trabalhadores avulsos portuários no que tange à execução de serviços no espaço dos operadores portuários privados.

Um ponto importante a ser destacado é que todas as constatações precedentes foram feitas a partir de um contexto local e que não seria adequado generalizar os resultados para outros portos do Brasil, sendo necessária, portanto, a reprodução do levantamento em outras redes de relacionamentos de outras regiões. Essa constatação foi feita a partir de entrevistas com gestores vinculados a outra rede de relacionamentos, fora daquelas 39 organizações identificadas por Weymer (2005). De acordo com os depoimentos, em determinadas situações a relação entre operadores portuários e trabalhadores avulsos se torna viável do ponto de vista de custo, uma vez que o fato de não ter vínculo empregatício é considerado como vantagem por parte dos contratantes (principais), evidenciando, portanto, a necessidade de aprofundar o recorte teórico desse estudo em outros trabalhos em diferentes contextos portuários.

\section{Referências}

BARDIN, L. Análise de conteúdo. 2. ed. Lisboa: Edições 70, 2009.

BESANKO, D. et al. A economia da estratégia. Porto Alegre: Bookman, 2005.

BRASIL. Lei n. 8.630, de 25 de fevereiro de 1993. Dispõe sobre o regime jurídico da exploração dos portos organizados e das instalações portuárias e dá outras providências. Diário Oficial [da] República Federativa do Brasil, Poder Legislativo, Brasília, DF, 25 fev. 1993. Disponível em: < http://www.planalto.gov.br/ccivil_03/Leis/L8630. htm>. Acesso em: 5 abr. 2011.

CHRISTEN, M.; IYER, G.; SOBERMAN, D. Job satisfaction, job performance, and effort: a reexamination using agency theory. Journal of Marketing, New York, v. 70, n. 7 , p. $137-150,2006$.

EISENHARDT, K. Agency theory: an assessment and review. Academy of Management Review, New York, v. 14, n. 7, p. 57-74, 1989.

GULATI, R. Alliances and networks. Strategic Management Journal, New York, v. 19, n. 3, p. 293317, 1998.

JENSEN, M.; MECKLING, W. Theory of the firm: managerial behavior, agency costs, and ownership structure. Journal of Financial Economics, New York, v. 3, n. 1, p. 305-360, 1976.

LIMA, C. R. M. Informação e regulação da assistência suplementar à saúde. Rio de Janeiro: E-papers Serviços Editoriais, 2005. 
NASCIMENTO, H. A. S. O nascimento de um novo trabalhador portuário: reestruturação produtiva e corporativismo. 1999. 250 f. Dissertação (Mestrado em Sociologia) - Universidade Estadual de Campinas, Campinas, 1999.

ROSS, S. The economic theory of agency: the principal's problem. American Economic Review, New York, v. 20, n. 2, p. 22-32, 1973.

VIEIRA, M. M. F.; VIEIRA, E. F. Geoestratégia dos espaços econômicos: transformação e poder no sítio portuário-retroportuário do Rio Grande, RS. Organizações Sociedade, v. 19, n. 7, p. 109-122, 2000.

WEYMER, A. Estrutura de relacionamento e respostas estratégicas das organizações do setor portuário de Rio Grande/RS. 2005. 226 f. Dissertação (Mestrado em Administração) - Universidade Federal do Paraná, Curitiba, 2005.

WEYMER, A.; MACHADO-DA-SILVA, C. L. Cooperação, competição e poder entre organizações do Porto de Rio Grande-RS. In: ASSOCIAÇÃO NACIONAL DE PÓSGRADUAÇÃO E PESQUISA EM ADMINISTRAÇÃO, 30., 2006, Salvador. Anais... Salvador: EnANPAD, 2006.

Recebido: 31/08/2010

Received: 08/31/2010

Aprovado: 10/11/2010

Approved: 11/10/2010 